\title{
UNVEILING THE MULTIPLE AND COMPLEX FACES OF FIDELITY
}

\author{
Fiorineschi, Lorenzo; Rotini, Federico \\ University of Florence
}

\begin{abstract}
Fidelity is one of the most important parameters to consider when dealing with prototypes, which affect the related costs and performances. Current literature contributions often rely on generic definitions of Fidelity based on the concept of closeness. However, the review performed in this paper revealed that Fidelity is a more complex concept, which considers (at least) eight main dimensions, mutually interrelated, and potentially characterized by many other potential sub-dimensions. The identified set has been applied to an industrial case study were a real engineering prototype has been assessed in terms of Fidelity. In particular, the case study application shows how the different dimensions can be interrelated each other. Furthermore, some important research hints have been highlighted in this paper, where the identified set of Fidelity dimensions paves the way for the related future activities.
\end{abstract}

Keywords: Prototyping, Fidelity, Design practice, Design for Additive Manufacturing (DfAM), Case study

Contact:

Fiorineschi, Lorenzo

University of Florence

Industrial Engineering

Italy

lorenzo.fiorineschi@unifi.it

Cite this article: Fiorineschi, L., Rotini, F. (2019) 'Unveiling the Multiple and Complex Faces of Fidelity', in Proceedings of the 22nd International Conference on Engineering Design (ICED19), Delft, The Netherlands, 5-8 August 2019. DOI:10.1017/dsi.2019.178 


\section{INTRODUCTION}

Prototypes are acknowledged to provide fundamental support in different disciplines such as Architecture, Product Development, Design, Software Development and Service Development (Exner et al., 2015), as reported in many literature contributions (e.g. Ullman (2010); Hallgrimsson (2012); Ulrich and Eppinger (2012); Hess and Summers (2013); Jensen, Elverum and Steinert (2017)). The plethora of research works about prototyping and prototypes also led to many different definitions (see the review of Jensen, Özkil and Mortensen (2016)), but generally speaking, a prototype can be considered an approximation of the final product, which can be realized for many purposes such as learning, communicating, refining and explore the design space (Camburn et al., 2017).

In this context, the approximation level of the prototype assumes a crucial role, because it affects the related performances and costs. For example, if on the one hand "high fidelity" prototypes (i.e. nearer to the final product) can certainly provide detailed information, on the other hand their realization costs can be prohibitive in certain situations (e.g. if more prototypes are needed to evaluate/test different early design solutions). Moreover, if prototypes are used for exploration purposes, recent research works suggest that "low fidelity" prototypes (i.e. rough and/or partial approximation of the final solution) should be preferred (Isa et al., 2015; Mathias et al., 2018; Ranscombe et al., 2017). In addition, it has been observed that Fidelity of prototypes should be carefully selected according to the audience to which they are destined (Elverum et al., 2016; McCurdy et al., 2006).

Unfortunately, although "Fidelity" is a very important parameter for prototypes, it is still a quite ambiguous term. More specifically, sometimes it is intended as the distance (or "closeness") between the general appearance of prototypes and the final product, while, in other circumstances, Fidelity refers to more specific sets of parameters. Therefore, notwithstanding the high number of valuable literature contributions about the influence of Fidelity on different aspects of prototyping, it is still impossible to extract detailed and generally valid indications/suggestions about this parameter.

This paper aims at unpacking the different meanings currently attributed to Fidelity and at arguing about the possible benefits arising by the introduction of a more comprehensive set of parameters to be used in place of the generic concept of closeness. Accordingly, after a short introduction to prototypes, a literature review has been performed about the currently available definitions of Fidelity (Section 2). Possible interconnections and causal relationships among parameters extracted from the review are introduced in Section 3, together with an illustrative example about an engineering prototype from a SME firm (Section 4). Section 5 reports comprehensive discussions about the identified Fidelity dimensions and the related case study application, providing a detailed description of the limits of this work, future developments and the expected impact. Eventually, Conclusions are reported in the last section.

\section{THE DIFFERENT DIMENSIONS OF FIDELITY}

Design research about prototyping aims at better understanding the related processes and/or at providing models, methods, guidelines and tools for supporting designers. For these purposes, prototypes of different nature can be used. Indeed, as approximation of the final product, prototypes can be realized in different ways, which can sensibly differ from those used to build the final product. Physically built prototypes (or physical prototypes) are very diffused through product design and development practice (Ullman, 2010). They can be realized with different materials, technologies and dimensions, according to the required design (or experimental) specifications. For example, physical prototypes can be manufactured manually (e.g. foam, paper or wire models), with classical materialsubtracting technologies, or with additive ones (Carfagni et al., 2018). Moreover, prototypes can be virtually realized, visualized and evaluated by means of CAE tools, where virtual and/or augmented reality can be used (also in a mixed way with physical models) to enhance interactions with stakeholders and for different purposes (e.g. Bordegoni et al. (2018); O'Hare et al. (2018)).

Different ways to realize a prototype may lead to different approximations of the final product. But the approximation level directly affects the information that can be extracted, and then can differently influence both work and how people feel about the work (Gerber and Carroll, 2012). Therefore, it is quite clear that Fidelity is one of the most important parameters to be considered when dealing with prototypes. However, Fidelity covers a wide range of characteristics, but a shared definition of them is still missing. 
One of the most generic definitions of Fidelity is that provided by Virzi (1989), who took inspiration from the Turing test to define High-Fidelity prototypes (which cannot be easily distinguished from the final product) and Low-Fidelity prototypes (which can be rapidly distinguished from the final product). This definition, like similar ones adopted in other literature contributions (Hallgrimsson, 2012; Houde and Hill, 1997; Yang, 2004; Zink et al., 2017), considers Fidelity as a sort of measure of a not well specified "closeness" between the prototype and the final product. This quite generic definition has been successfully used in some research works but some scholars felt the need to provide more focused meanings. In the following paragraphs, the results of our literature review are presented, concerning the contributions that report (directly or indirectly) more specific definitions of Fidelity.

The review has been performed initially by searching for "prototypes OR prototyping" and "fidelity" in the search engines of Scopus and Design Society databases. Major attention has been devoted to engineering (i.e. by refining the search on the "engineering" field in the Scopus search engine). Nevertheless, additional searches have been performed by analysing the references of the first set of identified articles, then partially extending the review to few contributions belonging to other disciplines (e.g. Industrial Engineering, Human-Computer interactions, etc.), leading to a set of 100 contributions.

Although the performed literature review is not representative for all the disciplines, it provides a first overview about how many different interpretations may be hidden behind the concept of closeness. McCurdy et al. (2006) made a similar work, but limited to the identification of five "dimensions" of Fidelity and of an intermediate level (mixed fidelity). We extended their work, by identifying a total of eight Fidelity dimensions (Table 1).

Table 1. Set of dimensions identified for the different meanings of Fidelity.

\begin{tabular}{|c|c|c|c|}
\hline No & Dimensions & Illustrative example from literature & Reference \\
\hline 1 & Data & $\begin{array}{l}\text { "How representative of the actual domain } \\
\text { data is the data employed by the prototype?" }\end{array}$ & (McCurdy et al., 2006) \\
\hline 2 & Form/Visualization & $\begin{array}{l}\text { "How refined should the prototype be from a } \\
\text { visual standpoint?" }\end{array}$ & (McCurdy et al., 2006) \\
\hline 3 & Functionality & $\begin{array}{l}\text { "How broadly is the functionality represented } \\
\text { within the prototype?" }\end{array}$ & (McCurdy et al., 2006) \\
\hline 4 & Interactivity & $\begin{array}{l}\text { "How are the interactive elements } \\
\text { (transitions, system responses to user inputs, } \\
\text { etc.) captured and represented to the user by } \\
\text { the prototype?" }\end{array}$ & (McCurdy et al., 2006) \\
\hline 5 & $\begin{array}{l}\text { Prototyping } \\
\text { technique }\end{array}$ & $\begin{array}{l}\text { "how well does the technique meet the } \\
\text { required level of detail?" }\end{array}$ & (Mathias et al., 2018) \\
\hline 6 & Material & $\begin{array}{l}\text { "These are preliminary prototypes constructed } \\
\text { with materials that are easy and fast to work } \\
\text { with and thus facilitate explorative } \\
\text { conversation with materials. These low- } \\
\text { fidelity prototypes..." }\end{array}$ & (Bao et al., 2018) \\
\hline 7 & Performance & $\begin{array}{l}\text { "To what level of detail is any one feature or } \\
\text { sequence represented?" }\end{array}$ & (McCurdy et al., 2006) \\
\hline 8 & Environment & $\begin{array}{l}\text { "The fidelity of the testing situation may } \\
\text { differ from the future usage situation on four } \\
\text { dimensions. First, the participant in a usability } \\
\text { test may be different from..." }\end{array}$ & (Sauer et al., 2010) \\
\hline
\end{tabular}

McCurdy et al. (2006) split the functionality dimension it in two parts, i.e. "breadth of functionality" (how many functions) and "depth of functionality" (detail at which a function is implemented). This subdivision is useful and still valid, but in our work we are more confident with the concept of Functionality as parameter to represent the number of functions implemented by the prototype (breadth of functionality). Then we adopted the parameter "Performance" to represent the level at which all the prototype's properties have been implemented for each function. Moreover, some dimensions summarized in Table 1 can be furtherly split in one or more specific sub-dimensions: e.g. scale and aesthetical appearance can be two potential sub-dimension of the Form/Visualization 
dimension. However, for the purposes of this work, we limit our attention on the main dimensions shown in Table 1, which can be generalized as it follows:

1. Data: closeness with the final product in terms of quantity and quality of processed data.

2. Form/Visualization: closeness with the final product in terms of scale, aesthetical appearance, tolerances, etc. Generally, this dimension covers all the attributes related to the geometry of the prototype.

3. Functionality: closeness with the final product in terms of quantity of implemented functions.

4. Interactivity: closeness with the final product in terms of quantity and/or quality of possible interaction with users and/or other stakeholders.

5. Prototyping technique: closeness with the final product in terms of manufacturing/realization process and related costs.

6. Material: closeness with the final product in terms of quantity and/or quality of material used for its realization (this dimension is valid only for physical prototypes).

7. Performance: closeness with the final product in terms of performances related to the implemented functions.

8. Environment: closeness of the prototyping environment with that expected for the final product in terms of available resources, quantity and/or quality of stakeholders (e.g. expertise of users).

According to the above-introduced definitions of the Fidelity dimensions, it is possible to observe that scholars, when talk about Fidelity, sometimes refer to one dimension singularly, while sometimes they use more dimensions concurrently. Table 2 reports an illustrative list of contributions using different dimensions. It is important to notice that occurrences shown in Table 2 are not representative of the actual diffusion of specific Fidelity dimensions. Indeed, frequencies may vary, depending on the discipline and the research objectives characterizing the reviewed contributions.

Table 2. Illustrative sample of contributions using one or more different dimensions of Fidelity shown in the precedent paragraph.

\begin{tabular}{|c|c|c|c|c|c|c|c|c|}
\hline \multirow[b]{2}{*}{ Reference } & & \multicolumn{7}{|c|}{ Dimensions } \\
\hline & 1 & 2 & 3 & 4 & 5 & 6 & 7 & 8 \\
\hline (Lim et al., 2006) & & & $\mathrm{X}$ & & & & & \\
\hline (Bao et al., 2018) & & & & & & $\mathrm{X}$ & & \\
\hline (Menold et al., 2017) & & & $\mathrm{X}$ & & & & & \\
\hline (Hannah et al., 2012) & & $\mathrm{X}$ & & & & $X$ & & \\
\hline (Jensen et al., 2018) & & $\mathrm{X}$ & & & & $\mathrm{X}$ & & \\
\hline (Jensen et al., 2017) & & & $X$ & & & & & \\
\hline (Sauer et al., 2008) & & $\mathrm{X}$ & $X$ & & & & & \\
\hline (Bonner and Van Schaik, 1998) & & $\mathrm{X}$ & $\mathrm{X}$ & & & & & \\
\hline (McCurdy et al., 2006) & $\mathrm{X}$ & $\mathrm{X}$ & $\mathrm{X}$ & $\mathrm{X}$ & & & $\mathrm{X}$ & \\
\hline (Duncan et al., 2017) & & $\mathrm{X}$ & $\mathrm{X}$ & & & & & \\
\hline (Rudd et al., 1996) & & & $\mathrm{X}$ & $\mathrm{X}$ & & & & \\
\hline (Mathias et al., 2018) & & & & & $\mathrm{X}$ & & & \\
\hline (Mueller et al., 2014) & & & $\mathrm{X}$ & & $\mathrm{X}$ & & & \\
\hline (Sauer et al., 2010) & & & & & & & & $\mathrm{X}$ \\
\hline (Wall et al., 1992) & & $\mathrm{X}$ & & & & $\mathrm{X}$ & & \\
\hline (Hare et al., 2014) & & $\mathrm{X}$ & $\mathrm{X}$ & & & & & $\mathrm{X}$ \\
\hline
\end{tabular}

\section{RELATIONSHIPS AMONG FIDELITY DIMENSIONS}

The set of dimensions extracted in Section 2 covers a wide range of aspects concerning the planning, the design and the use of prototypes. However, a simple list of dimensions can be too simplistic, because some interconnections can be found among them.

It is not possible to extract generally valid rules from the literature review performed in this work, but some preliminary considerations can be made. For example, in certain situations Functionality can be one of the most impacting dimensions when planning for prototypes. Indeed, it is quite trivial that static mock-ups are cheaper than fully functional prototypes with the same aesthetical appearance.

Once the number of functions expected for the prototype are planned, for each of them it is necessary to decide the Fidelity level along the Performance dimension. In this case, multiple sub-dimensions 
could also be considered (e.g. power consumptions, noise, duration of the parts implementing the functions, etc.). Required performances may affect the selection of materials used to build prototypes (e.g. with sufficient tensional strength), which in turn affect the selection of the prototyping technique. Moreover, also the Form and Visualization dimension influences decisions about the prototyping technique. Indeed, large prototypes or high quality surface finish may hinder the adoption of certain technologies. In turn, tolerances and surface finish may affect the performances of the implemented functions (e.g. affecting kinematics).

Additionally, the number of functions implemented by the prototype may affect its interactivity with the user (e.g. the actions characterizing a certain function may need to be activated and deactivated by the user). However, also certain environment conditions may hinder high fidelity levels for the Interactivity dimension (e.g. a prototype remotely controlled to fulfil safety requirements). Interactivity levels influence the Data dimension but also the Form and Visualization. Indeed, to have high levels for Interactivity, in some cases it could be necessary to build the prototype (or part of it) in the final product scale and appearance (e.g. control panels for electrical appliances).

The considerations made in this short paragraph introduce the complexity behind Fidelity, and demonstrate that, especially for engineering applications, the generic concept of "closeness" is not sufficient to perform comprehensive analysis and investigations aimed at better understanding the potentialities and roles of prototypes.

\section{APPLICATION EXAMPLE: THE WOOD GRINDER PROTOTYPE}

To better show what expressed in the previous section, here we report the case of an experimental wood grinder prototype built by a small firm (ten employees). In this case, the project started thanks to a public funding aimed at promoting innovation in small firms, where the realization of a demonstrative prototype was required as final project deliverable. This is a real case, where conflicting prototyping requirements and very limited economical resources led to the realization of a single physical prototype expected for both experimental and demonstrative purposes. The set of fidelity dimensions shown in Section 2 is applied to this prototype to argue about its applicability and the presence of the interconnections introduced in Section 3. The levels that we assigned for each dimension are shown in Table 3, and a detailed description of the assessment is reported in the following paragraphs. In particular, "Mixed" means that both low and high levels have been found for the same Fidelity dimension.

Table 3. Fidelity dimensions and related levels for the wood grinder prototype.

\begin{tabular}{ll} 
Fidelity dimension & Level \\
\hline Data & Low \\
Form/Visualization & Mixed \\
Functionality & Low \\
Interactivity & Low \\
Prototyping technique & Mixed \\
Material & High \\
Performance & Mixed \\
Environment & High \\
\hline
\end{tabular}

\subsection{Functionality and Performance}

The main function of the prototype was that of reducing wood particle sizes while an additional function was the reduction of the moisture content in the processed wood. While the performances related to the first function were satisfactory (Power consumption, quantity and quality of produced wood particles), the reduction of moisture was not sufficient to justify its implementation in the final product. Accordingly, it is possible to assert that the number of functions implemented by the prototype is higher than the final one. For this reason, we decided to assign "low" to the level of the Functionality dimension.

Moreover, the prototype was characterized by high noise, i.e. a negative performance from the two functions implemented by the prototype, to be reduced in the final product. Therefore, we conclude that the Performance parameter is high for certain objectives of the two functions while it is low for others. Accordingly, we assigned the "mixed" level. 


\subsection{Environment and Interactivity}

The final product was expected to be installed in plants were hopper, elevator and separating cyclone are necessary accessories for the grinder. A very similar environment was recreated in the experimental plant (Figure 1), but for safety requirements it was enclosed within a specific room, and the machinery was remotely controlled and monitored. Therefore, some interactions with the prototype (wood loading and output particles unloading) were not at high Fidelity levels. Moreover, additional interactions were required for experimental purposes (temperature monitoring, rotational speed and airflow regulations), but they were not expected in the final product.

For these reasons, we decide to assign "high" to the Environment dimension, and "low" to the Interactivity one.
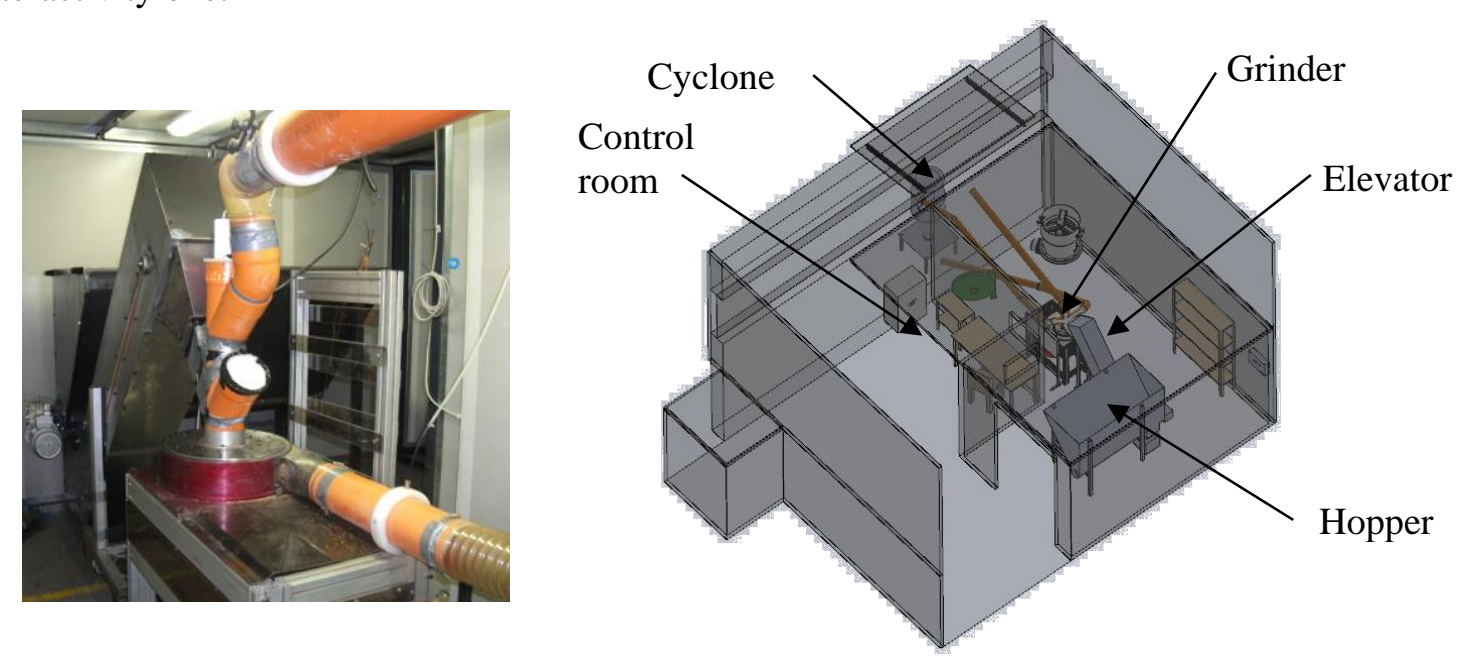

Figure 1. Front view and CAD model representing the layout of the experimental plant where the grinder prototype was installed. The surrounding environment is quite similar to that expected for the final product (high Fidelity for the Environment dimension).

\subsection{Data}

Due to the additional interactions introduced in the precedent paragraph, the prototype was equipped with monitors (Figure 2), transducers, cables etc. to acquire and process data. However, the final product is not expected to monitor all of these parameters, thus we assigned a low level to this dimension.

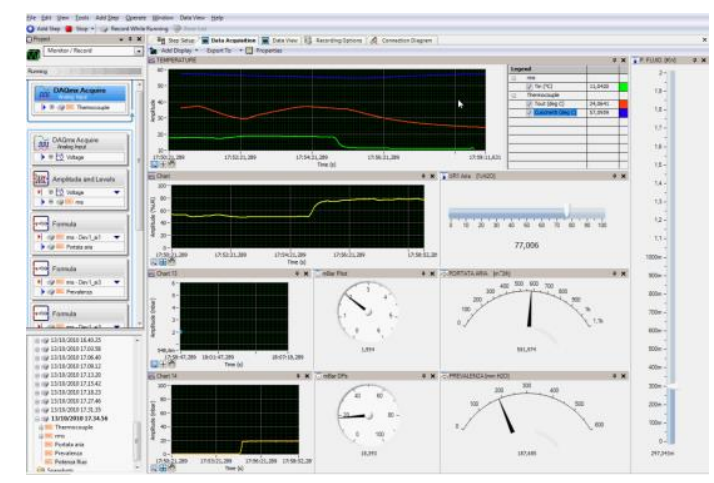

Figure 2. Data panel for prototype monitoring. None of this data is needed in the final product, then the data Fidelity dimension is a low-level.

\subsection{Form/visualization, Material and Prototyping Technique}

To allow full functionalities, the prototype's main body was built in real scale, by classical manufacturing techniques and completely in steel (Figure 3). However, it was designed to allow different testing configurations, and then some parts resulted to be more complicated than those expected for the final product. Moreover, as visible in Figure 1, some parts (e.g. connection tubes) were realized with low cost standard parts, and then the final appearance was not that expected for the 
final product. Consequently, it is possible to assert that the Material level is high, while the Form/Visualization level assumes different values, depending what is observed (e.g. the grinder's main body vs its overall embodiment made by an aluminium framework, plastic tubes and adhesive tape). Similarly, concerning the prototyping technique, it is difficult to assert which is the level of this parameter, because the main body was manufactured with the same process adopted for final product, but the other parts were not. Accordingly, we assigned "mixed" to both Form/Visualization and Prototyping technique levels.

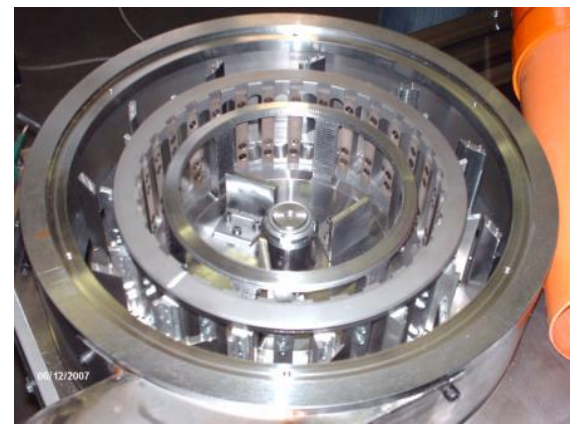

Figure 3. The grinder main body. Material and Prototyping technique are at high levels, but some parts have been opportunely designed for experimental purposes. Therefore, the Form/Visualization level for this part has a low level.

\section{DISCUSSIONS}

\subsection{Outcomes of this paper and related limits}

The observations performed in this paper unveil the complex nature of the multiple facets of Fidelity. The eight dimensions identified in Section 2 cover a wide range of parameters (sub-dimensions) characterizing prototypes and prototyping activities, whose comprehensive identification falls out of the scope of this paper. Indeed, sub-dimensions are case sensitive, since particular situations may highlight the presence of some of them, while hiding other ones.

In the prototype shown in Section 4, some possible sub-dimensions emerged quite easily, for example in the Performance dimension, where different parameters were identified (e.g. power consumption, quantity and quality of produced outcomes) for each function implemented by the prototype. Moreover, it also emerged that understanding the actual level reached by the Fidelity dimensions is a difficult task. Sometimes these difficulties are strictly related to the presence of evident subdimensions ("mixed" level cases), while in other cases, the metric to be used is unclear (e.g. when is it possible to assert that the level for a certain dimension is low or high?). In the latter ones, for the purposes of this paper we assigned the values in a quite subjective way. Therefore, it is currently impossible to extract a generally valid framework for multidimensional Fidelity analysis. Indeed, a single case study is not sufficient to verify the validity of the identified set, because many possible situations may characterize prototyping activities (e.g. iterative and/or parallel prototyping, different requirements and application fields, etc.), and then additional difficulties may arise.

Nevertheless, this work highlights that the argument is very complex and still needs to be investigated in deep. Accordingly, this paper provides a set of Fidelity dimensions that, although its preliminary nature, constitutes a reference starting point for future research activities.

\subsection{Hints for future research on Fidelity}

While the dimension extracted here come from a literature review mainly focused on Engineering Design, similar investigations should be performed on more extended sets of contributions to better cover the different disciplines. Besides this initial hint, uncertainties and observations emerged during the case study application also pave the way for potential research about Fidelity. Indeed, the identification of sub-dimensions, as well as the analysis of the interrelationships among dimensions, should be repeated on extended sets of cases studies where different prototyping conditions are considered. This kind of activities could lead to the definition of generally valid frameworks and/or guidelines for multidimensional Fidelity assessments. Accordingly, the identification of a robust set of 
metrics for performing assessments of each Fidelity dimension constitutes another important research hint.

\subsection{Potential impact of multidimensional Fidelity analysis}

Here in the following, some possible research arguments are reported, where comprehensive analysis of Fidelity dimensions could lead to relevant results for both industry and academia.

\subsubsection{Fidelity in idea generation activities}

Many works emphasize the use of "low fidelity" prototypes in early design phases or, more generally, in idea generation processes (e.g. Isa and Liem (2014); Mckenzie (2015); Bao, Faas and Yang (2018)). The low level of approximation is often expected to diminish or even to contrast design fixation, which instead can affect design outcomes obtained with high-fidelity prototypes.

However, which are the fidelity dimensions that mainly affect design or idea generation outcomes?

It is not clear whether different levels of Form, Functionality, Interactivity, Material, etc. support or hinder or, in general, affect creativity. This lack of information is crucial because hinders the possibility to develop more effective design methods based on the exploitation of prototypes. Accordingly, this paper provides a starting point for future reflections about the actual role of the different Fidelity dimensions in idea generation activities.

\subsubsection{Fidelity in prototyping strategies}

Recent works have been published about prototyping strategies (e.g. Camburn et al. $(2015,2017)$ ), and some of them propose to elicit information from past experiences, e.g. by interviewing expert designers (Hilton et al., 2015). Besides Fidelity, many other parameters exist that must be taken into account. For example, it is necessary to understand the number of prototypes needed to reach the final objective, as well as the techniques used to build them (e.g. subsystem isolation, iterative or parallel prototyping, etc. (Camburn et al., 2017)). Nevertheless, extracting comprehensive indications about Fidelity from design experiments or case studies could provide useful suggestions for the development of guidelines for the identification of prototyping strategies. In fact, that of prototyping costs is surely an overwhelming parameter, which is heavily affected by the Fidelity level (Virzi, 1989). More precisely, different levels of Functionality, Form/Visualization, Interactivity, Material, etc. certainly influence costs, but can also affect the prototyping results. Therefore, for different situations where prototypes are needed, the identification of the most suitable levels for each Fidelity dimension would lead to a more focused and effective planning of the prototyping process. For example, when prototypes are used to promote (internally or externally to the firm) new products, it is acknowledged that Fidelity influences audiences (Buchenau et al., 2000; Elverum et al., 2016). However, it is unclear if some of the Fidelity dimensions identified in this paper could be more relevant for specific situations/contexts. Consequently, this paper highlights the problem and paves the way for future research aimed at gathering this information, which would lead to better optimize costs and demonstrative performance of prototypes.

\subsubsection{Fidelity for selecting rapid prototyping technologies}

It is acknowledged and quite trivial that certain prototyping technologies (e.g. paper-board or foam prototypes) may not reach high Fidelity levels for certain dimensions. However, sometimes the selection of the most suited prototyping technology can be quite complex. For example, Additive Manufacturing technologies (AT) are currently spreading and their use for prototyping purposes constitutes a valid and well known resource (Carfagni et al., 2018). Nevertheless, the presence of a vast and continuously evolving variety of printers and materials, leads to non-negligible selection difficulties. Indeed, some printing technologies can be more suited for low-fidelity in the Functionality dimension, while they can ensure quite high fidelity levels for the Form/Visualization. Conversely, other AT allow to implement all required functions, but with limited surface details and limited performances (e.g. low cost Fused Deposition Method devices). Other more expensive AT may allow to reach high fidelity levels in terms of Form/Visualization, Performance and Material (e.g. Electron Beam or Direct Metal Laser Sintering technologies), but with sensibly higher costs.

The above-presented considerations suggest that a comprehensive planning of the levels desired for Fidelity dimensions could support the selection of the most suited printing technology. For example, 
the identification of correlations between the desired Fidelity levels and the performances of the available AT processes could potentially lead to the definition of methodological tools for selecting the proper AT. As highlighted in Section 5.2, to obtain such a kind of results it is first necessary to develop robust metrics for Fidelity assessments. Nevertheless, the observations made in this paper, can pave the way for research activities aimed at the development of prototyping selection guidelines based on Fidelity considerations.

\section{CONCLUSIONS}

The motivation that lead us to perform this research, initially came from the perceived impossibility to use the generic concept of "closeness" for comprehensively interpreting experimental and/or prototyping results. Accordingly, the work presented in this paper was focused on the identification of more extended and comprehensive definitions about Fidelity of prototypes. More specifically, we identified eight Fidelity dimensions, mutually interrelated, and potentially characterized by multiple sub-dimensions. The case study application revealed that the identified set can be applied to engineering prototypes, but several problems still need to be solved about Fidelity assessments. With the aim to bridge the existing gaps, some important research hints have been highlighted in this paper, where the identified set of Fidelity dimensions constitutes the potential reference for the related future activities.

\section{REFERENCES}

Bao, Q., Faas, D. and Yang, M. (2018), "Interplay of sketching \& prototyping in early stage product design", International Journal of Design Creativity and Innovation, Taylor \& Francis, Vol. 0349, pp. 1-23.

Bonner, J.V. and Van Schaik, P. (1998), "The use of high and low level prototyping methods for product user interfaces", Contemporary Ergonomics, pp. 253-257.

Bordegoni, M., Ferrise, F., Wendrich, R. and Barone, S. (2018), "Virtual and Mixed Prototyping Techniques and Technologies for Consumer Product Design Within a Blended Learning Design Environment", International Design Conference - Design 2018, pp. 183-192.

Buchenau, M., Francisco, I.S. and Suri, J.F. (2000), "Experience Prototyping”, Conference on Designing Interactive Systems: Processes, Practices, Methods, and Techniques, pp. 424-433.

Camburn, B.A., Dunlap, B., Gurjar, T., Hamon, C., Green, M., Jensen, D., Crawford, R., et al. (2015), “A Systematic Method for Design Prototyping”, Journal of Mechanical Design, Vol. 137 No. 8, pp. 081102.

Camburn, B.A., Viswanathan, V.K., Linsey, J., Anderson, D., Jensen, D., Crawford, R., Otto, K., et al. (2017), "Design prototyping methods: state of the art in strategies, techniques, and guidelines", Design Science, Vol. 3 No. e13, available at: https://doi.org/10.1017/dsj.2017.10.

Carfagni, M., Fiorineschi, L., Furferi, R., Governi, L. and Rotini, F. (2018), “The Role of Additive Technologies in the Prototyping Issues of Design", Rapid Prototyping Journal, Vol. 24 No. 7, pp. 1101-1116.

Duncan, B., David, M. and Ben, H. (2017), "Evolving lego: Prototyping requirements for a customizable construction kit", 21st International Conference on Engineering Design, ICED 2017, Vol. 4, pp. 297-306.

Elverum, C.W., Welo, T. and Tronvoll, S. (2016), "Prototyping in new product development : Strategy considerations", Procedia CIRP, Vol. 50, The Author(s), pp. 117-122.

Exner, K., Lindow, K., Stark, R., Stark, R., Bähr, B. and Nagy, E. (2015), “A transdisciplinary perspective on prototyping", IEEE International Conference on Engineering, Technology and Innovation/International Technology Management Conference (ICE/ITMC).

Gerber, E. and Carroll, M. (2012), ““'The psychological experience of prototyping”, “, Design Studies, Elsevier Ltd, Vol. 33 No. 1, pp. 64-84.

Hallgrimsson, B. (2012), Prototyping and Model Making for Product Design, Laurence King Publishing Ltd, London, available at: https://doi.org/10.1017/CBO9781107415324.004.

Hannah, R., Joshi, S. and Summers, J.D. (2012), “A user study of interpretability of engineering design representations", Journal of Engineering Design, Vol. 23 No. 6, pp. 443-468.

Hare, J., Gill, S., Loudon, G. and Lewis, A. (2014), "Active and passive physicality: making the most of low fidelity physical interactive prototypes", J. Design Research, Vol. 12 No. 4, pp. 330-348.

Hess, T. and Summers, J.D. (2013), “Case study: Evidence of prototyping roles in conceptual design”, Proceedings of the International Conference on Engineering Design, ICED13, Vol. 1 DS75-01, pp. 249-258.

Hilton, E., Linsey, J. and Goodman, J. (2015), ““Understanding the prototyping strategies of experienced designers", Proceedings - Frontiers in Education Conference, FIE, Vol. 2014, available at: https://doi.org/10.1109/FIE.2015.7344060.

Houde, S. and Hill, C. (1997), “What do prototypes prototype?”, in M., H., T., L. and P., P. (Eds.), Handbook of Human Computer Interaction, Elsevier Science B. V., Amsterdam, pp. 1-16. 
Isa, S.S. and Liem, A. (2014), "Classifying Physical Models and Prototypes in the Design Design Process: a Study on the Economical and Usability Impact of Adopting Models and Prototypes in the Design Process", Proceedings of the 13th International Design Conference DESIGN 2014, pp. 2071-2082.

Isa, S.S., Liem, A. and Steinert, M. (2015), "The Value of Prototypes in the Early Design and Development Process", 20th International Conference on Engineering Design (ICED 15), pp. 1-8.

Jensen, L.S., Nissen, L., Bilde, N. and Özkil, A.G. (2018), "Prototyping in Mechatronic Product Development: How Prototype Fidelity Levels Affect User Design Input”, International Design Conference - Design 2018, pp. 1173-1184.

Jensen, L.S., Özkil, A.G. and Mortensen, N.H. (2016), "Prototypes in Engineering Design : Definitions and Strategies", INTERNATIONAL DESIGN CONFERENCE - DESIGN 2016, pp. 821-830.

Jensen, M.B., Elverum, C.W. and Steinert, M. (2017), ““"Eliciting unknown unknowns with prototypes: Introducing prototrials and prototrial-driven cultures”, “, Design Studies, Elsevier Ltd, Vol. 49, pp. 1-31.

Lim, Y., Pangam, A., Periyasami, S. and Aneja, S. (2006), "Comparative Analysis of High- and Low-fidelity Prototypes for More Valid Usability Evaluations of Mobile Devices", Proceedings of the 4th Nordic Conference on Human-Computer Interaction: Changing Roles. ACM, pp. 14-18.

Mathias, D., Hicks, B., Snider, C. and Ranscombe, C. (2018), "Characterizing the Affordances and Limitations of Common Prototyping Techniques to Support the Early Stages of Product Development", International Design Conference - Design 2018, pp. 1257-1268.

McCurdy, M., Connors, C., Pyrzak, G., Kanefsky, B., Vera, A. and Field, M. (2006), "Breaking the Fidelity Barrier: An Examination of our Current Characterization of Prototypes and an Example of a MixedFidelity Success", Proceedings of the SIGCHI Conference on Human Factors in Computing Systems, pp. 1233-1242.

Mckenzie, D. (2015), “Generative Prototype Iteration in the Front End of the Design Process", DS82: Proceedings of the 17th International Conference on Engineering and Product Design Education (E\&PDE15), pp. 272-277.

Menold, J., Jablokow, K. and Simpson, T. (2017), "Prototype for X (PFX): A holistic framework for structuring prototyping methods to support engineering design”, Design Studies, Elsevier Ltd, Vol. 50, pp. 70-112.

Mueller, S., Im, S., Gurevich, S., Teibrich, A., Pfisterer, L., Guimbretière, F. and Baudisch, P. (2014), "WirePrint: 3D printed previews for fast prototyping", UIST '14: Proceedings of the 27th Annual ACM Symposium on User Interface Software and Technology, Honolulu, pp. 273-280.

O’Hare, J.A., Dekoninck, E., Giunta, L., Boujut, J. and Becattini, N. (2018), “Exploring the Performance of Augmented Reality Technologies in Co- Creative Sessions : Initial Results From Controlled Experiments", International Design Conference - Design 2018, pp. 405-416.

Ranscombe, C., Bissett-Johnson, K., Boa, D. and Hicks, B. (2017), "Designing with lego: Exploring the influence of low fidelity visualisation on collaborative design activities", 21 st International Conference on Engineering Design, ICED 2017, Vol. 8 No. DS87-8, pp. 269-278.

Rudd, J., Stern, K. and Isensee, S. (1996), “Low vs. high-fidelity prototyping debate”, Interactions, Vol. 3 No. 1 , pp. 76-85.

Sauer, J., Franke, H. and Ruettinger, B. (2008), "Designing interactive consumer products: Utility of paper prototypes and effectiveness of enhanced control labelling”, Applied Ergonomics, Vol. 39 No. 1, pp. 71-85.

Sauer, J., Seibel, K. and Ruttinger, B. (2010), "The influence of user expertise and prototype fidelity in usability tests", Applied Ergonomics, Vol. 41 No. 1, pp. 130-140.

Ullman, D.G. (2010), The Mechanical Design Process 4th Ed., Mc Graw HIll, New York, USA.

Ulrich, K.T. and Eppinger, S.D. (2012), Product Design and Development, 5th ed., Mc Graw Hill Irwin, New York, available at: https://doi.org/10.1016/B978-0-7506-8985-4.00002-4.

Virzi, R.A. (1989), "What can you learn from a low-fidelity prototype?", Proceedings of the Human Factors and Ergonomics Society Annual Meeting, Vol. 33 No. 4, pp. 224-228.

Wall, M.B., Ulrich, K.T. and Flowers, W.C. (1992), "Evaluating Prototyping Technologies for Product Design”, Research in Engineering Design, Vol. 3, pp. 163-177.

Yang, M.C. (2004), “An Examination of Prototyping and Design Outcome”, Proceedings of DETC 20042004 ASME Design Engineering Technical Conferences, pp. 1-6.

Zink, L., Böhmer, A.I., Hostetter, R., Lindemann, U. and Knoll, A. (2017), "The use of prototypes within agile product development Explorative Case Study of a Makeathon”, International Conference on Engineering, Technology and Innovation (ICE/ITMC), pp. 68-77.

\section{ACKNOWLEDGMENTS}

The authors acknowledge the contribution of "Fondazione Cassa di Risparmio di Pistoia e Pescia", which partially supported this research through the funding programme named "Bando Giovani e Ricerca 2016". 